\title{
Evidence of zeolitic-like domains in mesostructured aluminosilicates: FTIR spectroscopy of basic probe molecules
}

\author{
M.T. Sánchez ${ }^{\text {, J J. Agúndez }}$, J. Pérez-Pariente ${ }^{\text {a }}$, C. Márquez-Álvarez ${ }^{\text {a }}$, B. Onida ${ }^{\text {b }}$ and E. \\ Garrone $^{b}$
}

anstituto de Catálisis y Petroleoquímica, CSIC. C/ Marie Curie 2, Cantoblanco, 28049

Madrid, Spain. Tel: +34 915854928.*E-mail: c.marquez@icp.csic.es

${ }^{\mathrm{b}}$ Dipartimento di Scienza dei Materiali e Ingegneria Chimica, Politecnico di Torino, Corso

Duca degli Abruzzi, 24, 10129 Torino, Italy.

The acid properties of mesostructured aluminosilicates synthesized from gels precursors of colloidal ZSM-5 zeolite have been studied by FTIR spectroscopy of basic probe molecules (ammonia, $\mathrm{CO}$ and propene). It is shown that these materials possess stronger acid sites with higher thermal stability than those of conventional Al-MCM-41. These results explain the enhaced $\mathrm{m}$-xylene isomerization activity of these materials and are attributed to the presence of zeolitic-like domains in the aluminosilicate framework.

\section{INTRODUCTION}

Ordered mesoporous aluminosilicates are potential catalysts for reactions where large molecules are involved. However, these materials exhibit poor hydrothermal stability and acidic properties, due to the lack of crystalline ordering of the framework [1]. Aiming to obtain hydrothermally stable ordered mesoporous materials with high acid catalytic activity, several synthesis strategies have been developed, based on hydrothermal crystallization of zeolites concepts [2-6] (for an extensive review, see [7]). In an attempt to obtain order within the network, we synthesized mesostructured aluminosilicates using sols precursors of colloidal ZSM-5 zeolite to which the cationic surfactant cetyltrimethylammonium bromide (CTABr) was added to form the mesophases [8]. Materials with catalytic activity in the mxylene test reaction remarkably higher than that of conventional Al-MCM-41 were obtained. This suggests that the use of zeolite precursors led to an enhanced acidity of the mesoporous aluminosilicates, probably caused by a modification of the T-O-T connectivity in the vicinity of the protonic acidic sites. Besides, the isomerization/disproportionation ratios measured at isoconversion were notably lower than that of a ZSM-5 zeolite, suggesting a higher accessibility to the acidic sites [9]. XRD patterns of the calcined samples only showed a broad low-angle diffraction peak, attributed to a poorly ordered mesostructure, and evidenced that no zeolite crystalline domains with sizes larger than the detection limit (ca. $5 \mathrm{~nm}$ ) were present. In order to obtain evidences about the presence of zeolitic domains, pyridine adsorption as well as FTIR measurements were performed. However, pyridine adsorption data only showed a slightly higher acidity for the most active materials compared to conventional Al-MCM-41 and, on the other hand, no framework vibration bands that could be unambiguously assigned to zeolite building blocks were observed in the FTIR spectra [9].

In the present work, the acidic properties of these materials have been studied in deeper detail by means of FTIR spectroscopy of adsorbed basic probe molecules. The proton transfer ability to an acceptor molecule, such as ammonia or propene, and the capability to 
Lewis base coordination (CO) is evaluated aiming to provide evidences on the presence of zeolite type of order within the aluminosilicates framework.

\section{EXPERIMENTAL}

Mesostructured aluminosilicates were obtained from solutions precursors of colloidal MFI zeolite with molar composition: $x \mathrm{Al}_{2} \mathrm{O}_{3}: 25 \mathrm{SiO}_{2}$ : 6 TPA: $0.1 \mathrm{Na}_{2} \mathrm{O}: 530 \mathrm{H}_{2} \mathrm{O}$, $(\mathrm{x}=0.5$ and 0.8$)$. Tetrapropilammonium cations $\left(\mathrm{TPA}^{+}\right)$were introduced from TPA hydroxide and TPA bromide, with TPAOH/TPA molar ratio between 0.63 and 1 . Aluminium hydroxide was used as $\mathrm{Al}$ source, which was obtained by precipitation of an aqueous solution of aluminium sulfate $\left(\mathrm{Al}_{2}\left(\mathrm{SO}_{4}\right)_{3} \cdot 18 \mathrm{H}_{2} \mathrm{O}\right.$, Aldrich) with an aqueous solution of ammonia ( $25 \mathrm{wt} \%$, Panreac). $\mathrm{Al}(\mathrm{OH})_{3}$ was washed and filtered with abundant deionized water and finally was dissolved in a TPAOH solution $\left(40 \mathrm{wt} \%\right.$, Alfa). Subsequently, additional $\mathrm{TPA}^{+}$cations were introduced from $\mathrm{TPABr}$ (98 wt $\%$, Aldrich), when needed. Afterwards, a diluted $\mathrm{NaOH}$ aqueous solution and the Si source, tetraethyl orthosilicate (TEOS, 98\%, Merck) were added stepwise. The resulting solution was stirred at room temperature for $15 \mathrm{~h}$. Finally, the solution was placed into an oven for hydrothermal treatment, in the temperature range 333-373 K. In order to obtain a mesophase, a $20 \mathrm{wt} \%$ aqueous solution of cetyltrimethylammonium bromide (CTABr, Aldrich) was slowly added to the colloidal zeolite precursor sol with stirring. The flocculate obtained was aged during $3 \mathrm{~h}$ at room temperature in static condition, filtered, washed and dried. The surfactant was removed by calcination at $550^{\circ} \mathrm{C}$ in a $\mathrm{N}_{2}$ stream during $1 \mathrm{~h}$ and in an air stream (100 $\left.\mathrm{ml} \mathrm{min}^{-1}\right)$ during $6 \mathrm{~h}$. Two reference MCM-41 materials, an all-silica (Si$\mathrm{MCM}-41$ ) and an aluminosilicate with $\mathrm{Si} / \mathrm{Al}$ ratio of 11 (Al-MCM-41) were prepared as reported in $[10,11]$.

Chemical analyses were performed by inductively coupled plasma optical emission spectrometry (ICP-OES) using an ICP Perkin-Elmer Winlab Optima 3000 DV instrument. The samples were previously digested by fusion in a Claisse Flusy-30 instrument, using a metaborate and lithium tetraborate (1:1 ratio by weight) melting solution, and solved in an aqueous nitric acid solution $(10 \mathrm{wt} \%)$. Nitrogen adsorption-desorption isotherms of calcined samples were obtained using a Micromeritics TriStar 3000 instrument. Samples were evacuated at $623 \mathrm{~K}$ for $30 \mathrm{~h}$ before analysis. FTIR measurements were carried out in transmission mode using thin self-supporting sample wafers. Absorbance was normalized to a wafer thickness of $3 \mathrm{mg} \mathrm{cm}^{-2}$ in all experiments. The samples were activated under dynamic vacuum $\left(<10^{-3}\right.$ mbar) for $1 \mathrm{~h}$ at different temperatures within an IR cell allowing in-situ thermal treatments and gas dosage. Spectra were collected using a Bruker FTIR Equinox 55 equipped with an MCT cryodetector working at $2 \mathrm{~cm}^{-1}$ resolution in the $4000-400 \mathrm{~cm}^{-1}$ wavenumber range. Ammonia $\left(\mathrm{NH}_{3}\right)$ and carbon monoxide $(\mathrm{CO})$ were adsorbed at $298 \mathrm{~K}$ and nominal $77 \mathrm{~K}$, respectively, on samples previously outgassed at 573,673 and $773 \mathrm{~K}^{-\mathrm{NH}_{3} \text { and }}$ $\mathrm{CO}$ were introduced by successive pulses until 100 and 40 mbar were reached, respectively. An FTIR spectrum was recorded after each dosage. In the case of propene, a 40 mbar single pulse was introduced at $298 \mathrm{~K}$, and FTIR spectra were recorded during the oligomerization process. For all probe molecules, FTIR spectra were also recorded at decreasing equilibrium

Table 1. Composition and textural properties of calcined mesoporous aluminosilicates

\begin{tabular}{|lccc|}
\hline Sample & $\mathrm{Si} / \mathrm{Al}$ & $\begin{array}{c}\mathrm{S}_{\mathrm{BET}} \\
\left(\mathrm{m}^{2} \mathrm{~g}^{-1}\right)\end{array}$ & $\begin{array}{c}\text { Pore volume } \\
\left(\mathrm{cm}^{3} \mathrm{~g}^{-1}\right)\end{array}$ \\
\hline MZ-H & 15 & 1017 & 1.19 \\
MZ-L & 28 & 1256 & 1.39 \\
Al-MCM-41 & 11 & 763 & 1.19 \\
\hline
\end{tabular}


pressures, by pumping down to $10^{-3}$ mbar in successive steps.

\section{RESULTS AND DISCUSSION}

The chemical composition and textural properties of the calcined mesoporous aluminosilicates selected for characterization of their acidic properties by FTIR spectroscopy of adsorbed basic probe molecules are reported in Table1. Sample MZ-L, which was obtained from a solution precursor of colloidal ZSM-5 with a Si/Al ratio of 25 and $\mathrm{TPAOH} /(\mathrm{TPAOH}+\mathrm{TPABr})=0.88$, aged at $60^{\circ} \mathrm{C}$ for $36 \mathrm{~h}$, exhibited a low activity in m-xylene conversion, close to that of the reference material Al-MCM-41 [9]. Sample MZ-H was synthesized from a solution with a $\mathrm{Si} / \mathrm{Al}$ ratio of 15.6 and $\mathrm{TPAOH} /(\mathrm{TPAOH}+\mathrm{TPABr})=1$, aged at $80^{\circ} \mathrm{C}$ for $42 \mathrm{~h}$. This latter sample possesses similar $\mathrm{Si} / \mathrm{Al}$ ratio and slightly larger surface area than Al-MCM-41. However, its catalytic activity was one order of magnitude higher [8], indicating a stronger acidity. A comparable enhancement of the catalytic activity of sample MZ-H relative to Al-MCM-41 can be observed in the propene oligomerization reaction at $298 \mathrm{~K}$ monitored by FTIR (Fig. 1). The growth of the alkyl C-H stretching bands (Fig. 1, left) and C-H and C-C bending bands (Fig. 1, right) with increasing propene-catalyst contact time indicates that oligomerization is taking place [12]. The catalytic activity of samples MZ-H and Al-MCM-41 is compared in Fig. 1 (inset), in which the band area of the $\mathrm{C}-\mathrm{H}$ asymmetric stretching of methyl groups $\left(2963 \mathrm{~cm}^{-1}\right)$, normalized by the sample thickness, has been plotted as a function of time. The results indicate that, for earlier reaction times, propene oligomeritazion occurs 2.5 times faster on $\mathrm{MZ}-\mathrm{H}$ than on Al-MCM-41, thus supporting the hypothesis of the existence of stronger Brønsted sites in the MZ-H material.

Fig. 2 reports FTIR spectra in the O-H streching region for samples outgassed at 573 (left) and $773 \mathrm{~K}$ (right). After treatment at $573 \mathrm{~K}$ a band at about $3745 \mathrm{~cm}^{-1}$, assigned to the $\mathrm{O}-\mathrm{H}$ stretching band of isolated silanols is observed. All the spectra show a broad absorption at lower wavenumbers, more prominent for sample Si-MCM-41 (curve 1), attributed to hydroxyls interacting via $\mathrm{H}$-bonding. After treatment at $773 \mathrm{~K}$, the aforementioned peak at $3745 \mathrm{~cm}^{-1}$ sharpens, due to the dehydroxylation process, which leads to an increased population of isolated $\mathrm{Si}-\mathrm{OH}$ groups, at the expenses of H-bridged and geminal silanols. At both temperatures, this band is more intense for MZ materials than all-silica and Al-MCM-41,
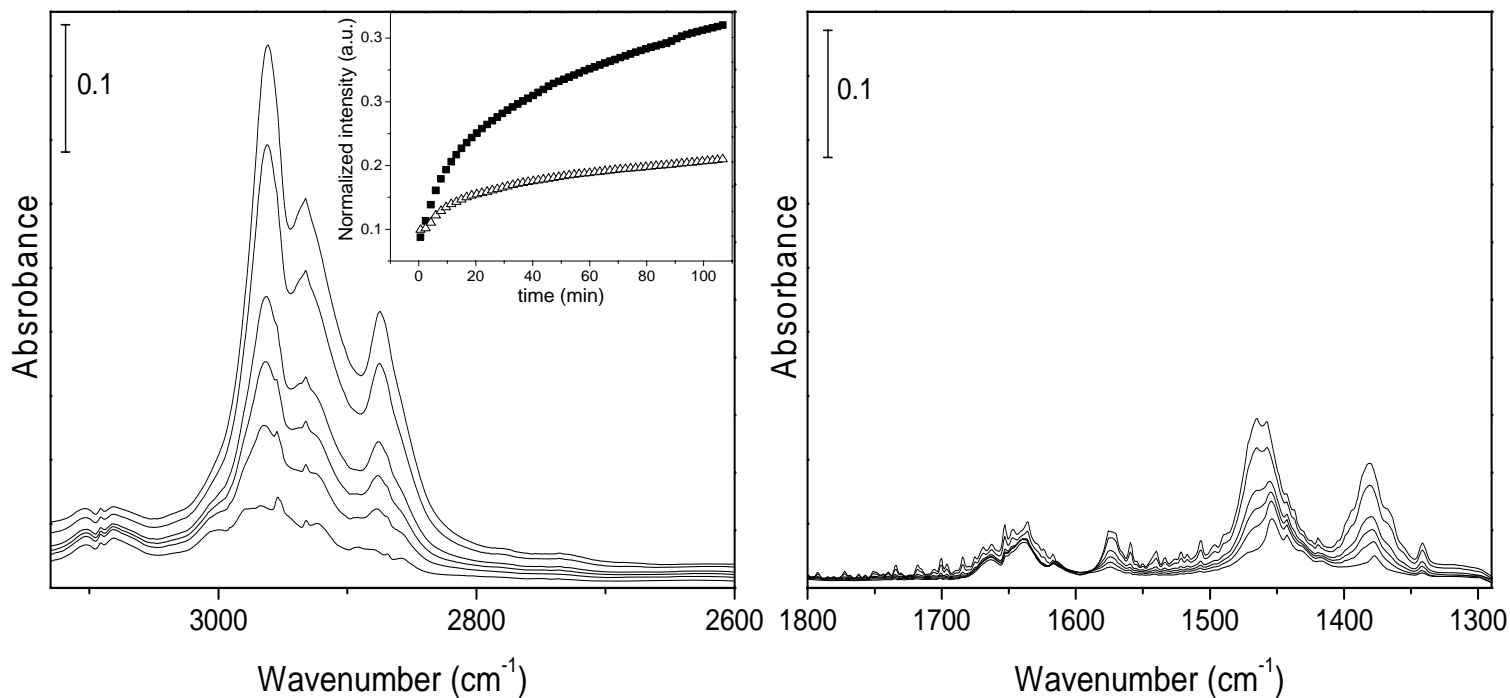

Fig. 1. Difference spectra of 40 mbar of sample MZ-H in contact with 40 mbar of propene at $298 \mathrm{~K}$ $(0.6,5,9,17,35,58,70,93,107 \mathrm{~min})$ after outgassing at $773 \mathrm{~K}$. The spectrum of the pretreated sample has been subtrated to every spectrum. Inset: normalized area of the $v_{\text {as }}\left(\mathrm{CH}_{3}\right)$ band at 2963 $\mathrm{cm}^{-1}$ for samples MZ-H (squares) and Al-MCM-41 (triangles). 

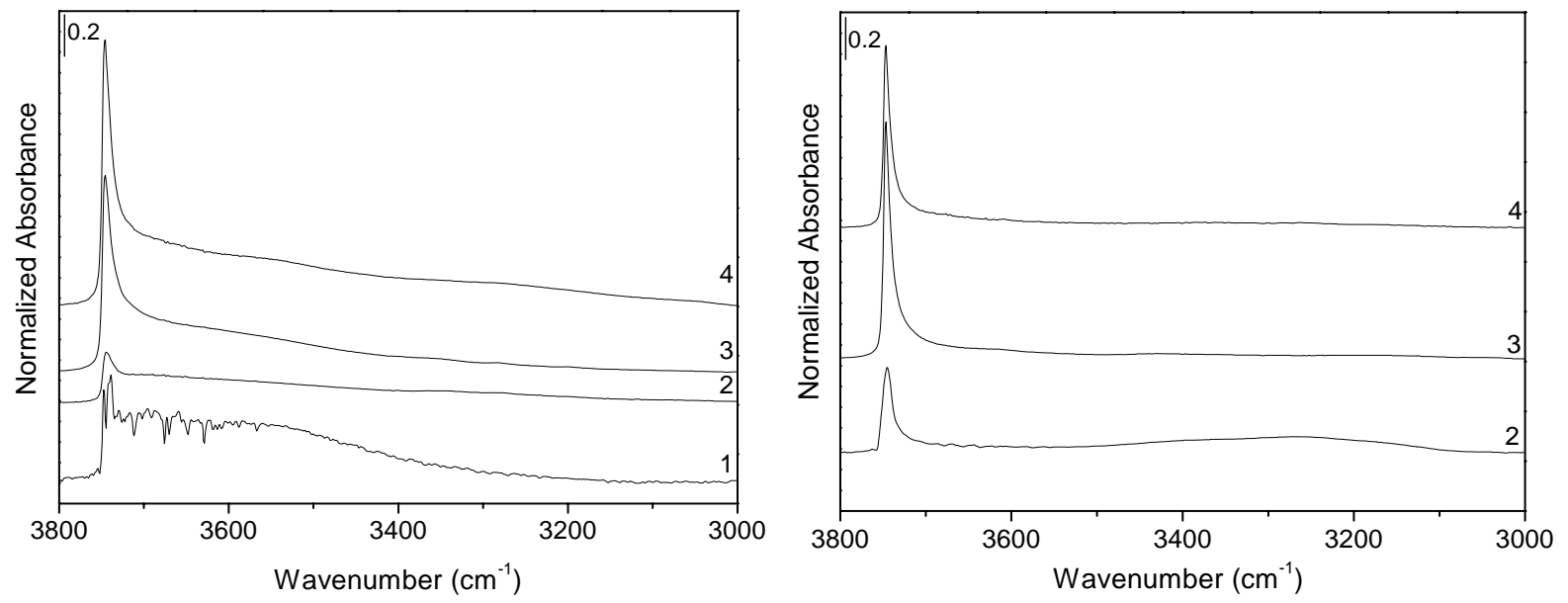

Fig. 2. FTIR spectra in hydroxyls region of samples Si-MCM41 (1); Al-MCM-41 (2); MZ-H (3) and MZ-L (4), outgassed at $573 \mathrm{~K}$ (left) and $773 \mathrm{~K}$ (rigth).

indicating a higher population of isolated silanols for $\mathrm{MZ}$ samples. The asymmetric tailing at the low frequency side of the band at $3745 \mathrm{~cm}^{-1}$ suggests the presence of several O-H species at the surface and is likely to correspond to hydroxyl species more acidic than isolated silanols [13]. However, bands characteristic of strongly acidic $\mathrm{Si}(\mathrm{OH}) \mathrm{Al}$ sites, that occur in the region around $3600 \mathrm{~cm}^{-1}$ in zeolites [14,15], are not detected. These results are in agreement with measurements of pyridine adsorption, which showed the presence of Brønsted sites of medium strength [9].

A thorough analysis of the acidic properties has been intended by $\mathrm{NH}_{3}$ and $\mathrm{CO}$ adsorption. Fig.3 (left) shows difference spectra of samples after ammonia adsorption at 298 $\mathrm{K}$ and evacuation at $10^{-3}$ mbar. Ammonia is mostly adsorbed on Brønsted sites by proton transfer, giving rise to an $\mathrm{NH}_{4}^{+}$bending band located at $1545 \mathrm{~cm}^{-1}$. Such band, which is present in Al-containing samples, but not in Si-MCM-41, does not disappear after outgassing, thus indicating that an irreversible process is taking place and suggesting that stable complexes are formed between ammonia and the Brønsted sites. Adsorption of ammonia also led to a decrease of the isolated silanol band $\left(3745 \mathrm{~cm}^{-1}\right)$, but a progressive restoration of the band was observed as ammonia evacuation proceeded. This result evidences a reversible
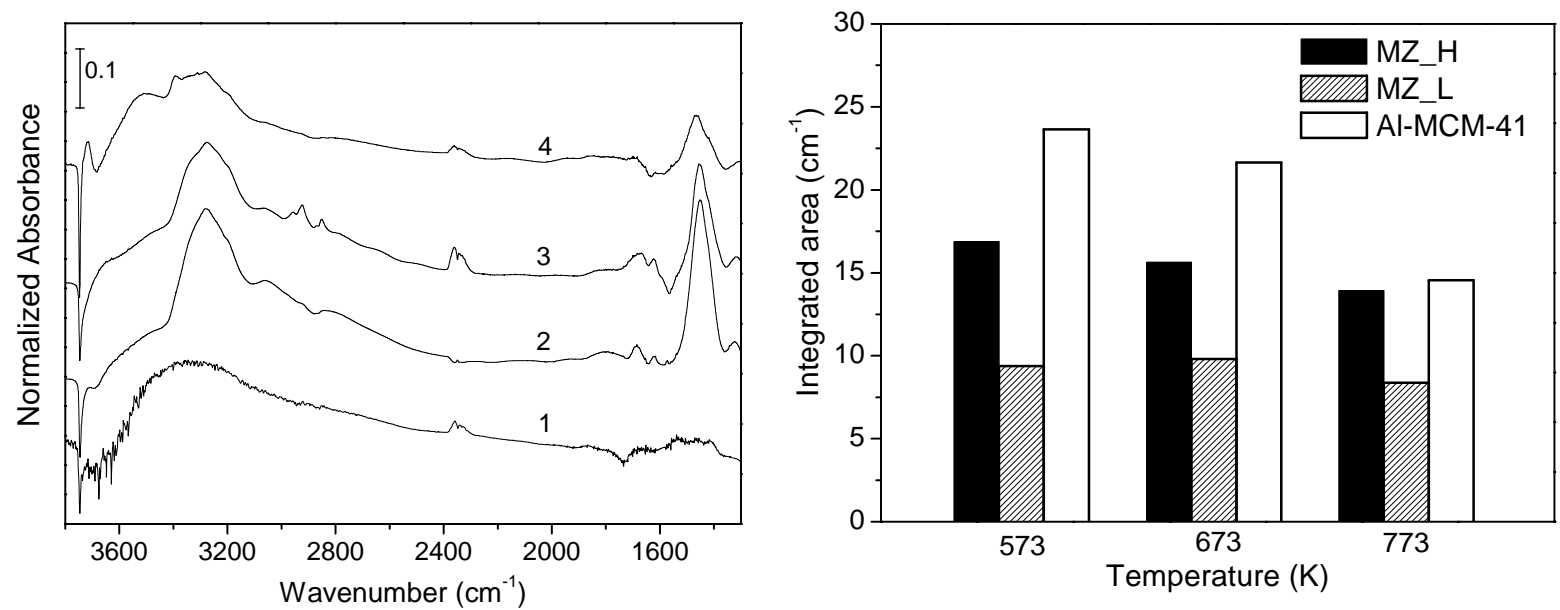

Fig. 3. Left: Difference FTIR spectra after dosage of 100 mbar of ammonia and evacuation at $298 \mathrm{~K}$ on samples Si-MCM41 (1); Al-MCM-41 (2); MZ-H (3) and MZ-L (4), outgassed at $573 \mathrm{~K}$. The spectrum of the corresponding pretreated sample has been subtracted to every spectrum. Right: $\mathrm{NH}_{4}^{+}$band area measured using different pre-treatment temperatures. 
weak hydrogen bonding interaction between silanol groups and ammonia. However, silanol band was not completely restored in any of the samples after ammonia evacuation, as it appears as a negative band in Fig. 3. Nonetheless, such small loss of silanol band intensity does not seem to be related to Brønsted acidity, as it occurs for sample Si-MCM-41, whose spectrum does not show the ammonium band.

It is worth noting that the $\mathrm{NH}_{4}{ }^{+}$band area decreases for sample Al-MCM-41 as the pre-treatment temperature increases from 373 to $573 \mathrm{~K}$ (Fig.3, rigth), indicating a loss of Brønsted sites due to dehydroxylation. However, the band area remains nearly constant for MZ samples, which reveals a higher thermal stability of the Brønsted sites in MZ mesoporous aluminosilicates.

Difference FTIR spectra recorded during the progressive $\mathrm{CO}$ desorption at $77 \mathrm{~K}$ are shown in Fig. 4 for samples MZ-H and Al-MCM-41, outgassed at 573 and $773 \mathrm{~K}$. At high coverage two bands dominate the spectra at 2156 and $2138 \mathrm{~cm}^{-1}$, the former due to the interaction between $\mathrm{CO}$ and isolated silanols and the latter due to adsorbed $\mathrm{CO}$ in a liquid-like phase $[16,17]$. At both temperatures, the intensity of the former band is higher for $\mathrm{MZ}_{-} \mathrm{H}$, thus suggesting a higher population of isolated $\mathrm{Si}-\mathrm{OH}$ groups in this sample, in agreement with Fig 2. At low coverage, a shoulder at ca. $2176 \mathrm{~cm}^{-1}$ can be seen for both samples, which can be attributed to $\mathrm{CO}$ adsorbed on Brønsted sites. A band decrease with pre-treatment temperature would be expected, however, the opposite can be observed. Such results suggest that weak Lewis sites are formed, as a band corresponding to $\mathrm{CO}$ adsorbed on those Lewis sites would be located at about $2176 \mathrm{~cm}^{-1}$, overlapping with the band assigned to $\mathrm{CO}$ interacting with $\mathrm{Si}(\mathrm{OH}) \mathrm{Al}$ species [16,18]. Moreover, in the spectra of both samples outgassed at $573 \mathrm{~K}$, a band located at $2228 \mathrm{~cm}^{-1}$ is clearly observed, which is assigned to
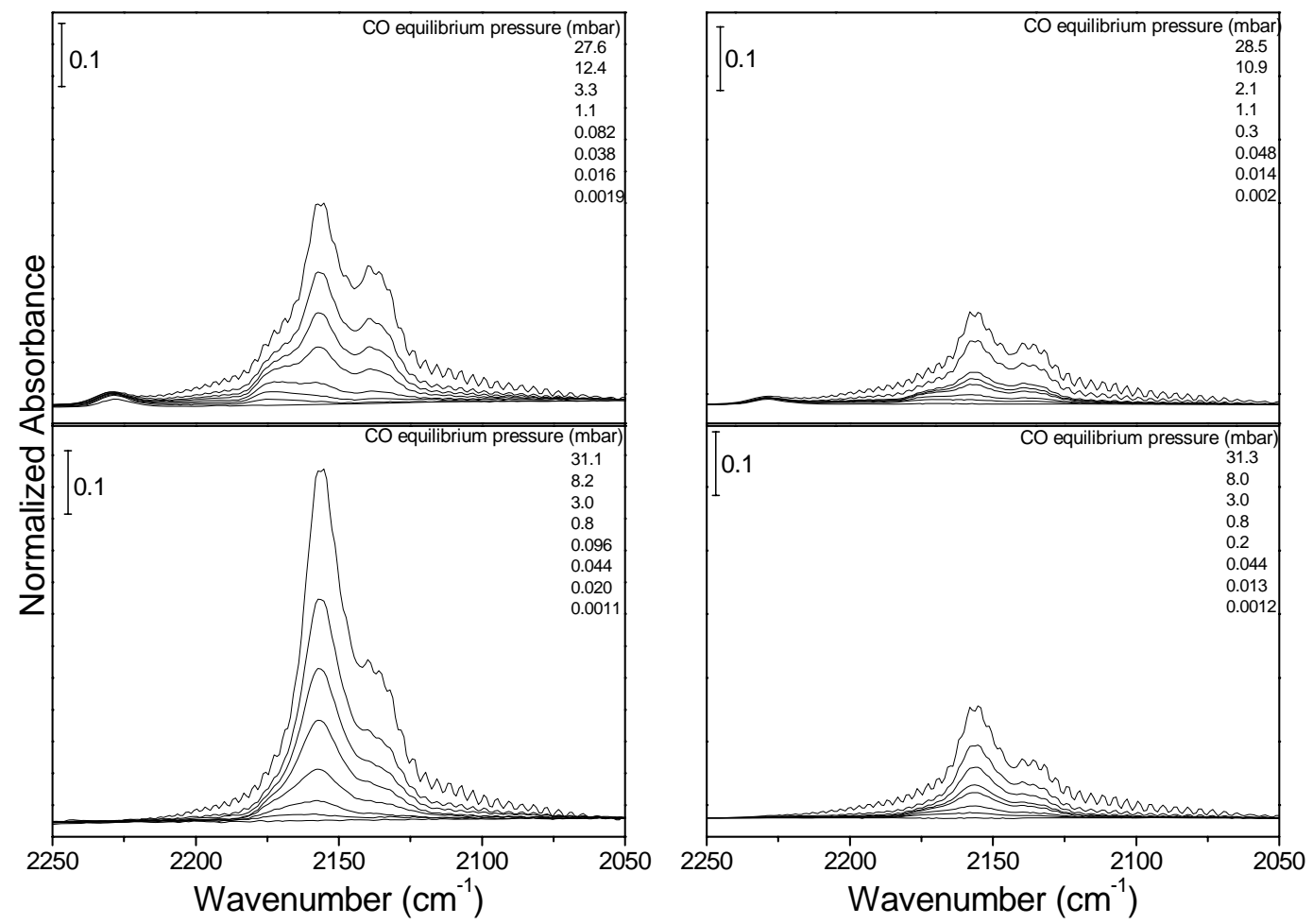

Fig. 4: Difference spectra of $\mathrm{CO}$ adsorbed at nominal $77 \mathrm{~K}$ at decreasing $\mathrm{CO}$ equilibrium pressure on samples MZ-H (left) and Al-MCM-41 (rigth), outgassed at $573 \mathrm{~K}$ (bottom) and $773 \mathrm{~K}$ (top). The spectrum of the corresponding pretreated sample has been subtracted to every spectrum. 
strong Lewis sites [18]. These results indicate that Lewis sites are created when the samples are outgassed at the highest temperature, which can be attributed to the thermal dehydroxylation process suggested by the ammonia adsorption results shown above.

\section{CONCLUSIONS}

The use of solutions precursors of colloidal ZSM-5 zeolite to synthesize mesoporous aluminosilicates has been shown to allow increasing the catalytic activity in propene oligomerization and m-xylene conversion compared to a conventional Al-MCM-41 material, indicating an enhanced surface acidity. Furthermore, Brønsted acid sites showed a higher thermal stability. These results support that the use of solutions precursors of colloidal zeolite can lead to the generation of zeolitic-like domains within the aluminosilicate framework.

\section{ACKNOWLEDGEMENTS}

This work has been supported by MEC, project MAT2003-07769-C02-02 and CAM-CSIC, project 200560M009.

\section{REFERENCES}

[1] A. Corma; V. Fornés; V. Navarro; J. Pérez-Pariente; J. Catal. 148 (1994) 569

[2] S. P. Naik; A. Chiang; R. Thompson; Microp. Mesop. Mater., 60 (2003) 213-224.

[3] A. Karlsson; M. Stöcker; R. Schmitd, Microp. Mesop. Mater. 27 (1999) 181; A. Karlsson; M. Stöcker; K. Schäfer, Stud. Surf. Sci. Cat. 125 (1999) 61; A. Karlsson; M. Stöcker; K. Schäfer, Stud. Surf. Sci. Cat. 129 (2000) 99.

[4] M. J. Verhoef; P. J. Kooyman; J. C. van der Waal; M. S. Rigutto; J. A. Peters; H. van Bekkum, Chem. Mater. 13 (2001) 683

[5] Y. Liu; W. Zang; T. J. Pinnavaia, J. Am. Chem. Soc. 122 (2000) 8791; Y. Liu; T. J. Pinnavaia, Chem Mater. 14 (2002) 3; Y. Liu; T. J. Pinnavaia, J. Am. Chem. Soc. 125 (2003) 2376

[6] Z. Zhang, Y. Han, F-S. Xiao, S. Qiu, L. Zhu, R. Wang, J. Am. Chem. Soc. 123 (2001) 5014; Y.Han. S. Wu, Y. Sun, D. Li. F-S. Xiao, Chem Mater. 14 (2002) 1144; Y. Di, Y. Yu, Y. Sun, X. Yang, S. Lin. M. Zhang, S. Li, F.-S. Ciao, Microp. Mesop. Mater. 62 (2003) 221.

[7] J. Pérez-Pariente, I. Díaz; J. Agúndez; C.R. Chimie 8 (2005) 569-578.

[8] J. Agúndez; I. Díaz; C. Márquez-Álvarez; E. Sastre; J. Pérez-Pariente; Stud. Surf. Sci. Cat. 154 (2004) 2907

[9] M.T. Sánchez; J. Agúndez; M. Grande; E. Sastre; J. Pérez-Pariente; C. Márquez-Álvarez; Actas do XX Simpósio Ibero-americano de Catálise. (2006)

[10] I. Díaz, J. Pérez-Pariente and E. Sastre, Stud. Surf. Sci. Catal. 125 (1999) 53.

[11] M. Boveri, J. Aguilar-Pliego, C. Márquez-Alvarez, J. Pérez-Pariente and E. Sastre, Stud. Surf. Sci. Catal. 158 (2005) 1549.

[12] R. Chiappetta; S. Bodoardo; F. Geobaldo; F. Fajula; E. Garrone; Res. Chem. Intermed. 25 (1999) 111-129.

[13] B. Bonelli; B. Onida; J.D. Chen, A. Galarneau; F. di Renzo; F. Fajula; E. Garrone; Microp. Mesop. Mater 67 (2004) 95-106.

[14] B. Onida; F. Geobaldo; F. Testa; R. Aiello; E. Garrone; J. Phys. Chem. B. 106 (2002) 1684-1690.

[15] B. Onida; L. Borello; B. Bonelli, F. Geobaldo; E. Garrone; J. Catal.. 214 (2003),191-199.

[16] K. Góra-Marek; M. Derewi'nski; P. Sarv; J. Datka; Catal Today. 101 (2005) 131-138.

[17] A. Zecchina; S. Bordiga; C. Lamberti; G. Spoto; L. Carnelli; C. Otero Areán, J. Phys. Chem. 98 (1994) 9577-9582.

[18] F. Di Renzo; B. Chiche; F. Fajula; S. Viale; E. Garrone; Stud. Surf. Sci. Cat. 101 (1996) 851.

Keywords: mesostructured aluminosilicates, crystalline framework, colloidal ZSM-5, FTIR spectroscopy, basic probe molecules 